\title{
LA RENTA BÁSICA Y EL PODER DE NEGOCIACIÓN DE "LOS QUE VIVEN CON PERMISO DE OTROS"*
}

\author{
DANIEL RAVENTÓS y DAVID CASASSAS \\ Universidad de Barcelona
}

\section{PALABRAS CLAVE ADICIONALES}

Ciudadanía, Democracia, Dominación, Independencia socioeconómica, Libertad, Pobreza, Propiedad, Trabajo.

\section{ADDITIONAL KEYWORDS}

Citizenry, Democracy, Domination, Socioeconomic Independence, Freedom, Poverty, Property, Work.

RESUMEN. Sin independencia socioeconómica no hay libertad. Las grandes desigualdades generan inmensas desproporciones de poder. Las grandes asimetrías de poder que existen en nuestras sociedades dan lugar a un problema de falta de libertad real para una gran parte de la población. Esta parte de la población, nada insignificante desde el punto de vista numérico, no tiene garantizada la existencia ciudadana puesto que carece de libertad como no-dominación. La Renta Básica de ciudadanía constituye un instrumento capaz de hacer real el derecho de existencia de toda la población a través, entre otros medios, de un aumento del poder de negociación de los pobres y de los dominados.

ABSTRACT. Freedom becomes impossible without individuals' socioeconomic independence. The great inequalities generate enormous disparities of power. The great asymmetries of power characteristic of current societies give rise to a lack of real freedom that affects most of the population. This portion of the population, which is far from being insignificant from a numerical point of view, has no guarantee of its citizen existence since it lacks freedom as non-domination. Basic Income constitutes a valuable mechanism for making the right to existence of the whole population a reality, since it would increase the power of negotiation of poor and dominated people.

*Este texto ha sido elaborado en el marco del proyecto de investigación BFF2002-04394-C0201, financiado por el Ministerio de Ciencia y Tecnología y el FEDER.

E-mail: danielraventos@ub.edu; casassas@eco.ub.es

Revista Internacional de Sociología (RIS)

Tercera Época, nº 34, Enero-Abril, pp. 187-201, 2003. 
La pretensión de este texto no es otra que la de explorar el vínculo existente entre libertades políticas, por un lado, y propiedad, por el otro, una propiedad que debe ser entendida como independencia socioeconómica, como independencia material con respecto a los demás. Y, más concretamente, la de analizar en qué sentido una Renta Básica de ciudadanía podría ayudar a conseguir dicha independencia socioeconómica. En otras palabras, nuestro objetivo es examinar si la Renta Básica constituye un buen instrumento para garantizar la existencia ciudadana. En este sentido, conviene tener presente, como telón de fondo del análisis que se realizará, el hilo conductor que opera entre dos realidades aparentemente tan alejadas, en el tiempo y en lo que respecta a la sensibilidad desde la que nacen, como lo son la apuesta político-institucional del magistral crítico de la democracia, Aristóteles, partidario de excluir a los pobres de la ciudadanía, y la articulación, durante el siglo XIX, del socialismo político, radicalmente democrático no tanto en el sentido etimológico del término, como en el sentido que se le ha dado históricamente, esto es, como "gobierno de los pobres" - unos "pobres" que, por otro lado, son, más que nunca, mayoría'.

\section{LIBERTAD Y PROPIEDAD}

Por un lado, plantea Aristóteles la conveniencia de excluir a los pobres, a los no propietarios, de la polis. No tiene sentido — sostiene el Estagirita - pretender que individuos que no tienen la subsistencia material asegurada y que, por lo tanto,

\footnotetext{
${ }^{1}$ Que hoy los pobres son mayoría quizá no sea algo controvertido; que cada vez hay más pobres, quizás tampoco; pero que cada vez haya más diferencias entre ricos y pobres posiblemente no sea algo comúnmente aceptado. Sin embargo, nosotros estamos firmemente convencidos de que así es. Algunos datos apuntalan esta convicción. Los 84 individuos más ricos del mundo poseen una riqueza que excede el PIB de China, un país de 1.300 millones de habitantes. En 1998, Michael Eisner, director general de Disney, cobraba 576,6 millones de dólares, lo que representaba 25.070 veces el ingreso medio de los trabajadores de esta misma empresa. Ese mismo año, un solo ciudadano de Estados Unidos, Bill Gates, disponía de más riqueza que el $45 \%$ de los hogares de aquel país (Too Much, invierno de 1999; The Nation, 19 de julio de 1999). Actualmente, el 5\% de los hogares con mayor poder adquisitivo de Estados Unidos dispone de casi el 50\% de la renta nacional. Mientras tanto, 80 países en el mundo cuentan con una renta per cápita inferior a la que tenían hace una década. La mitad de nuestra especie, la mitad más desheredada y vulnerable, 3.000 millones de personas, vive con menos de 2 dólares al día y, de éstos, 1.300 millones lo hacen con menos de 1 dólar diario. El economista norteamericano Robert Frank (1999) explica que, del conjunto de la ciudadanía de su país, el $1 \%$ más rico se embolsó el $70 \%$ de toda la riqueza generada desde mediados de la década de 1970. Para el Reino de España no hay datos equiparables que sean públicos. Pero es muy probable, según expertos fiscales que llevan años rastreando el terreno, que los datos puedan ser igualmente escandalosos, hasta el punto de que se haya optado por mantenerlos en secreto (Raventós y Francisco, 2002).
} 
"dependen del permiso de otros para vivir" porque están sometidos a la discrecionalidad más arbitraria por parte de quienes los han de contratar, puedan desarrollar una vida política libre de chantajes y, al fin y al cabo, pensar con auténtica independencia de juicio. No tiene sentido pretender, en último término, que estos individuos puedan cultivar las virtudes y "ser lo que pueden ser": "realizarse", entre otras cosas en tanto que ciudadanos.

Por el otro lado, veintitrés siglos más tarde, los communards - los "comunistas", podría decirse - del París de 1871, tal y como los fotografía Marx, subrayan la necesidad de asumir que el viejo esquema de Sieyés era demasiado simple: el llamado "tercer estado" - la sociedad civil, en definitiva - había quedado escindido en dos segmentos, el de unos burgueses industriales realmente libres, por un lado, $y$, por el otro, el de un auténtico ejército de trabajadores asalariados -aunque tampoco en todos los casos- sin recursos y, por tanto, dependientes de la arbitrariedad de los propietarios. En este sentido, tras la Comuna de París latía el reclamo, por parte de los más desfavorecidos del tercer estado de Sieyés, de unos derechos económicos y sociales - de ciudadanía - sin los cuales las libertades formales conquistadas en Francia entre 1789 y 1848 eran vistas como puro papel mojado.

Si volvemos a la aseveración de Marx recogida en la nota 2, nos percatamos fácilmente de las claras resonancias repúblicanas que esconden tales afirmaciones: la asunción de la necesidad de la propiedad para poder hablar de una noción no vacía, no banalizada de libertad aparece de un modo diáfano. No resulta ninguna novedad afirmar que la esencial vulnerabilidad de los trabajadores asalariados fue siempre algo de especial interés en las preocupaciones políticas de Marx.

En definitiva, parece que el republicanismo histórico ha tenido siempre claro que hablar de "ciudadanía" sin tomar en consideración las condiciones materiales de los supuestos "ciudadanos" puede empujar hacia un auténtico callejón sin salida o, simplemente, tratarse de un ejercicio de mera palabrería.

En ningún caso se afirma con lo que se ha planteado hasta el momento que la participación política y la "virtud cívica" - por utilizar terminología propia de la tradición republicana - a ella asociada sean realidades imposibles sin la propiedad, sin la independencia material. Sin ir más lejos, el grueso de la historia del movimiento obrero, los sujetos activos del cual se han hallado siempre amenazados

\footnotetext{
${ }^{2}$ Nos permitimos la licencia de poner palabras de Marx en boca de Aristóteles por lo clarificador que resulta tal anacronismo. El fragmento de las "Glosas marginales del programa del Partido Obrero alemán", donde podemos encontrar al Marx más genuinamente republicano, del que se ha extraído esta expresión reza, como sigue: “[...] el hombre que no dispone de más propiedad que su fuerza de trabajo ha de ser, de forma necesaria, en cualquier estado social y de civilización, esclavo de otros hombres, de aquéllos que se han adueñado de las condiciones materiales de trabajo. Y no podrá trabajar ni, por lo tanto, vivir, si no es con su permiso" (la cursiva es nuestra) (Marx, 1981).
} 
por una más que posible carestía de recursos básicos, obligaría a poner en tela de juicio una afirmación de este tipo. Lo que se pretende subrayar es, sencillamente, la existencia de un vínculo causal que hay que atender con especial esmero. En efecto, existe una fuerte correlación entre la propiedad, entendida como independencia material ${ }^{3}$ - más adelante se analizará cómo puede concretarse dicha "propiedad"- y la posibilidad de una plena inclusión en la ciudadanía. En otras palabras, lo que se pretende es destacar la importancia de manejar cierta idea de propiedad para hablar de libertades individuales en un sentido no vacuo del término.

Dicho de forma sucinta: esto es así porque esta independencia material otorga a los individuos el poder de negociación necesario para poder llevar a cabo de forma efectiva los planes de vida propios y, de este modo, evitar la posibilidad de quedar convertidos en meros instrumentos de terceros. Y todo ello, mirando "de frente a los demás" (Pettit, 1999). En definitiva, esta independencia material confiere a los individuos el poder de negociación necesario para hacer realidad la máxima kantiana según la cual el hombre debe ser un fin en sí mismo y, por tanto, no debe ser tratado como un instrumento 4 .

\section{PROPIEDAD COMO PODER DE NEGOCIACIÓN}

Pero, ¿cómo se concreta dicho poder de negociación? Cabe tomar como referencia la útil distinción de Elster (1991), para quien los principales factores determinantes de la fuerza negociadora son los tres siguientes: en primer lugar, las preferencias temporales - dicho de otro modo, la valoración que hacen los individuos del paso del tiempo-; en segundo lugar, la aversión o propensión a correr riesgos; y, finalmente, los recursos de partida con que los individuos cuentan - los "valores de desacuerdo", dicho en la terminología propia de la teoría microeconómica-:

\footnotetext{
${ }^{3}$ No necesariamente como "autopropiedad", el concepto central del esquema filosófico-político de Nozick, alrededor del cual se erige su influyente teoría de la justicia (Nozick, 1974). Tal y como se plantea en el pormenorizado análisis de Mundó (2003), "la conclusión importante consiste en que, para que prevalezca la libertad efectiva, o autonomia, debe haber restricciones sobre la autopropiedad, lo cual es paradójico, puesto que es la autonomía lo que nos hace atractiva la autopropiedad, aunque sea a través de una confusión desafortunada. Lo que hace más atractiva la tesis de la autopropiedad es lo que en realidad nos hace rechazar la autopropiedad irrestricta." Añade Mundó: “[...] para evitar que haya personas que vivan a expensas de otras -como los trabajadores carentes de propiedad-es necesario imponer restricciones a la autopropiedad" (los subrayados son del autor).

${ }^{4}$ Conviene destacar que la hermenéutica kantiana actual ofrece interesantes aproximaciones a la obra del filósofo de Königsberg que lo reivindican como un claro exponente de la tradición republicana. Véase Bertomeu (2003).
} 
"lo que nos queda si se rompen las negociaciones"s.

¿Qué debe entenderse por "preferencias temporales"? No es dificil imaginar la situación de un joven falto de recursos al que la urgencia para resolver su situación de inestabilidad económica - y vital — lo empuje a atar precipitadamente acuerdos que no lo beneficien en absoluto. En palabras de Elster (1991: 95), "el resultado [de una negociación] favorece a la parte menos impaciente, que puede decir de manera creíble que no le importa esperar". Dicho a la inversa y con un ejemplo que puede resultar clarificador: el hecho de que un licenciado en Sociología conceda muestras de urgencia anima al empresario que lo quiere contratar, a través de una empresa de trabajo temporal, para efectuar encuestas en unas condiciones laborales escandalosas a hacerle una oferta a la baja, convencido de que el joven sociólogo preferirá esta oferta "mala" "hoy", a alargar el proceso de negociación en favor de posibles futuras mejores ofertas. En definitiva, la "paciencia", la capacidad de espera constituye un factor clave para una posición negociadora convincente.

Parece razonable imaginar también que este mismo joven se mostrará menos dispuesto a correr riesgos en el proceso de negociación. Evitará, por ejemplo, apostar temporalmente por formas de trabajo alternativas que impliquen el consumo de ciertos ahorros que haya podido acumular. Si bien es cierto que tiene poco que perder, la desaparición de cierto colchón mínimo de recursos que haya podido articular para su seguridad económica puede resultar especialmente trágica. Pues bien, en este punto cabe señalar que ciertos resultados de la teoría social establecen, en relación con la actitud ante el riesgo, que un excesivo conservadurismo por parte de los contendientes en la mesa de negociación tiende a constreñir su conjunto de resultados favorables (Elster, 1991).

Finalmente, resulta evidente que no es lo mismo romper unas negociaciones laborales con unos recursos considerables a nuestra disposición, que hacerlo sin contar con ningún tipo de sostén —-con unos "valores de desacuerdo bajos", según la terminología propia de la teoría económica-. Es precisamente en esta dirección en la que cabe entender la importancia de las cajas de resistencia de los sindicatos, creadas con el objetivo de asegurar el sostenimiento material de los trabajadores en caso de rompimiento de negociaciones y de huelgas de larga duración ${ }^{6}$. Si el joven en cuestión se halla totalmente falto de recursos propios que puedan asegurar su sostén material durante un periodo de tiempo significativo,

\footnotetext{
${ }^{5}$ Este análisis es en buena medida subsidiario del realizado en Casassas y Loewe (2001). Asimismo, Germán Loewe realizó a uno de los autores de este artículo algunas oportunas observaciones en relación con el pasaje que sigue.

${ }^{6}$ Directísimamente relacionada con esta afirmación vaya la siguiente muestra empírica. El sindicato mayoritario vasco, ELA, promueve las huelgas más largas de las Comunidades Autónomas Vasca y Navarra. ELA es el único sindicato que cuenta con caja de resistencia. El mismo secretario
} 
RIS

REVISTA INTERNACIONAL DE SOCIOLOCIA

No 34, Enero-Abril, 2003

DANIEL RAVENTÓS y DAVID CASASSAS

difícilmente podrá negarse a propuestas que realmente no le convengan.

¿Puede actuar la Renta Básica precisamente como "caja de resistencia"? Dicho en términos más generales, ¿puede conferir una Renta Básica al joven del ejemplo una mayor fuerza negociadora? Antes de responder a estas dos preguntas, debemos precisar qué entendemos por Renta Básica? .

\section{UNA DEFINICIÓN COMENTADA DE RENTA BÁSICA}

Utilizaremos, por clara y comprensiva, la siguiente definición: Renta Básica es un ingreso pagado por el Estado a cada miembro de pleno derecho de la sociedad incluso si no quiere trabajar de forma remunerada, sin tomar en consideración si es rico o pobre 0 , dicho de otra forma, independientemente de cuáles puedan ser sus otras posibles fuentes de renta, y sin importar con quien conviva ${ }^{8}$.

"Un ingreso pagado por el Estado". El término "Estado" puede hacer referencia aquí a una institución jurídico-política de ámbito geográfico superior al de los estados-nación actualmente existentes -incluyan éstos a su vez sólo a una nación o a más de una, como sería este último el caso del Reino de España-; o puede referirse a ámbitos jurídico-políticos menores que el del estado-nación: comunidades autónomas, por ejemplo. Aquí no nos estamos refiriendo a la idoneidad del ámbito geográfico para la aplicación de la Renta Básica, sino a que su pago puede ser diseñado por distintos niveles de la administración pública: Unión Europea, gobierno central o gobiernos autonómicos.

"A cada miembro de pleno derecho de la sociedad". En otras palabras, a todo miembro de la ciudadanía del espacio geográfico considerado. Si los residentes han de percibir o no la Renta Básica es algo que ha suscitado cierta polémica. Somos de la opinión de que los residentes también deberían percibir la Renta Básica, con la condición adicional, si se quiere, de un tiempo mínimo de residencia continuada. Sea como sea, y pese a que en los distintos modelos de financiación de la Renta Básica se observen variaciones por lo que respecta a la cuantía - por ejemplo, en algunos de ellos se proponen distintas cantidades según las edades, y

\footnotetext{
general actual de dicho sindicato, José Elorrieta, comentaba a uno de los autores de este artículo que tales huelgas son posibles -junto con una actitud más combativa que la de CCOO y UGT, que ha distanciado completamente a ELA del PNV-precisamente gracias a la existencia de la caja de resistencia. Cabe recordar que ELA tiene más delegados sindicales que CCOO y UGT juntas. Vale la pena añadir que es recomendable, para deshacer el deplorable y extendido error de dar por supuesta la conexión de PNV con el sindicato ELA, leer el útil texto de Uribarri (2002).

${ }^{7}$ Una selección bibliográfica en castellano sobre la Renta Básica, constantemente actualizada, puede encontrarse en www.redrentabasica.org.

${ }^{8}$ Ésta es la definición que hemos utilizado en otros escritos. Los párrafos siguientes, que amplían y precisan dicha definición, tienen su origen en Raventós (2002).
} 
en otros se discute la necesidad o no de incluir a los menores-, la Renta Básica defendida en todos los casos constituye una cantidad monetaria que recibirían los ciudadanos individualmente - no por núcleos familiares, por ejemplo-y de forma universal, esto es, sin quedar condicionada al hecho de caer en determinados niveles de pobreza, por ejemplo.

"Incluso si no quiere trabajar de forma remunerada". Muy a menudo se interpreta "trabajo" como sinónimo de "trabajo remunerado" o "empleo". En otros escritos ya hemos desarrollado nuestra opinión al respecto, pero sirva ahora un breve resumen de tales materiales. El trabajo puede ser definido como una actividad que produce un beneficio que es externo a la ejecución misma de la actividad, beneficio que puede ser disfrutado por otros ${ }^{10}$. El trabajo asalariado constituye una parte del conjunto que incluye todos los tipos de trabajo. En efecto, el trabajo asalariado, en consonancia con la estipulación del trabajo que se ha hecho, noes más que una de las posibles formas de trabajo. Muy importante, ciertamente, pero sólo una forma más de trabajo. Considerar que el trabajo asalariado constituye el único tipo de trabajo significa establecer que otras actividades, tan importantes como el trabajo doméstico o el trabajo voluntario no remunerado, no son trabajo. En realidad, si el trabajo asalariado o por cuenta ajena fuese considerado la única actividad digna de ser incluida en la definición de trabajo, nos veríamos forzados a realizar la injustificada afirmación según la cual en el espacio económico del Reino de España, en la actualidad, sólo hay entre un 35 y un $40 \%$ de la población "trabajando". Lógicamente, de aquí se podría inferir que el restante 60 o $65 \%$ de la población "no trabaja". Con todo, existen buenas razones para afirmar que resulta más adecuada una clasificación del trabajo que distinga entre los siguientes tipos de trabajo: 1) trabajo con remuneración en el mercado; 2) trabajo doméstico; y 3) trabajo voluntario ${ }^{11}$. Queda claro, pues, que no estar realizando un trabajo remunerado no equivale a no estar desempeñando trabajo alguno, puesto que puede ser que se esté realizando trabajo doméstico o trabajo voluntario. Por otro lado, divagar sobre la ordinalidad - y no digamos sobre la cardinalidad — de la utilidad social de distintos trabajos constituye un ejercicio extremadamente difícil e infecundo ${ }^{12}$. En cualquier caso, lo que debe tenerse presente es el hecho de que afirmar que la Renta Básica sería percibida por todo miembro de pleno derecho

\footnotetext{
${ }^{9}$ Véanse al respecto las reflexiones recogidas en el Informe al Club de Roma de Giarini y Lietdke (1998), así como las de Zubero (2001).

${ }^{10}$ Se trata de una definición poco modificada respecto de la que ofrece Van Parijs (1996).

${ }^{11}$ Para un tratamiento más sistemático de estos tres tipos de trabajo, véase Raventós (1999). Para una discusión sobre el "derecho al trabajo" y su comparación con la propuesta de la Renta Básica, véanse Noguera (2001) y Noguera y Raventós (2002a, 2002b).

${ }^{12}$ Dos simples ejemplos pueden ayudar a vislumbrar la dimensión de lo que estamos afirmando: ¿cuántas veces, supongamos, es socialmente más necesario el trabajo de un camarero de determinado bar musical que el trabajo doméstico de una madre soltera con tres hijos?; ¿cuántas veces, volvamos a
} 
de la sociedad "incluso si no quiere trabajar de forma remunerada" no equivale a postular que la mayor parte de la población que no trabajase remuneradamente no estaría realizando alguna actividad propia de alguno de los otros dos tipos de trabajo señalados, el doméstico y el voluntario.

"Sin tomar en consideración si es rico o pobre o, dicho de otra forma, independientemente de cuáles puedan ser sus otras posibles fuentes de renta". A diferencia de los subsidios condicionados - a un determinado nivel de pobreza-, la Renta Básica la recibiría tanto un rico como un pobre, tanto un broker que gane millones de euros como un indigente de los barrios más pobres de cualquier ciudad. Este hecho, que puede resultar chocante a los que se aproximen por primera vez a la propuesta de la Renta Básica, cuenta con diversas justificaciones, unas de tipo normativo y otras de tipo técnico-administrativo, que han sido desarrolladas en otros lugares ${ }^{13}$. No estará de más, sin embargo, ofrecer algunas breves indicaciones al respecto.

En primer lugar, y en relación con las razones de tipo normativo que se han aducido en favor de la universalidad de la Renta Básica, cabe señalar que si ésta es concebida como un derecho de ciudadanía, como implícitamente puede desprenderse de la definición que se ha apuntado, se excluye toda condición adicional, por ejemplo, la riqueza, el sexo o el nivel de competencia de los individuos. Permitámonos una analogía que puede resultar clarificadora: tampoco el derecho ciudadano al sufragio universal impone condiciones adicionales a las de ciudadanía.

En segundo lugar - y con ello se abordan ya algunos de los argumentos de tipo técnico que han venido a sostener la incondicionalidad de la Renta Básica-, es preciso hacer constar que la asunción de la estigmatización que conlleva la percepción de los subsidios - condicionados- de pobreza anima a apostar por subsidios universales que se hallen garantizados de modo incondicional. Técnicamente, los subsidios condicionados requieren, debido precisamente a su carácter condicional, controles administrativos que, incluso en el caso de funcionar bien, esto es, sin corruptelas añadidas, resultan muy costosos.

Sin embargo, aun admitiendo todo lo apuntado hasta aquí, todavía podría haber quien considerase intuitivamente inadmisible darle a un rico acaudalado

suponer, es socialmente más necesario el trabajo de un profesor universitario de lenguas escandinavas que el de una monitora de cursos de salvamento de montaña en condiciones extremas? No obstante, y sin entrar en el resbaladizo terreno de la definición de la utilidad social del trabajo, conviene subrayar que, desde una perspectiva republicana, existen trabajos remunerados que son perfectamente calificables como perniciosos y otros trabajos no remunerados que pueden ser vistos como muy beneficiosos para buena parte de la sociedad.

13 Véanse, por ejemplo, Van Parijs (1992, 1996) y Van der Veen, Groot y Lo Vuolo (2002). También la argumentación desarrollada por el senador del brasileño Partido de los Trabajadores Eduardo M. Suplicy (2002) resulta interesante en este punto. 
una Renta Básica. De hecho, si se asume que la distribución de la renta no se vería alterada con respecto a la situación actual y que, además, habría que añadir una Renta Básica, tal reticencia tendría todo el sentido del mundo. Pero no es éste el caso. Todas - o casi todas- las propuestas solventes de financiación de una Renta Básica apuntan a una integración de dicha medida en el seno del sistema fiscal que se da de forma tal que la cantidad de recursos sustraída finalmente a los más ricos resulta netamente superior a la que reciben como Renta Básica ${ }^{14}$. En otras palabras, los más pobres siempre ganan con la Renta Básica, mientras que los más ricos siempre pierden ${ }^{15}$.

"Sin importar con quien conviva". Aunque existen algunas propuestas que introducen una Renta Básica por hogar con el objetivo de no penalizar a la cada vez mayor porción de la población de mayor edad que vive sola, el hecho de que la Renta Básica sea individual hace que su percepción sea completamente independiente de la forma de convivencia elegida: pareja heterosexual tradicional, pareja homosexual, agrupación de miembros de distintas generaciones en el mismo hogar, grupo de amigos, etc.

Realizada la explicación de nuestra definición de Renta Básica, nos hallamos en condiciones de recuperar las dos preguntas planteadas más arriba. Recordémoslas. ¿Puede actuar la Renta Básica precisamente como "caja de resistencia"? En términos más generales, ¿puede conferir una Renta Básica al joven del ejemplo una mayor fuerza negociadora? Parece razonable pensar que la seguridad en los ingresos que la garantía de una Renta Básica supondría impediría que los trabajadores se viesen impelidos a aceptar una oferta de trabajo de cualquier condición. Dicho en términos más precisos, desde el momento en que su salida del mercado de trabajo - su posición de retirada o fallback position- resultara practicable, la relación laboral se mostraría menos coercitiva (Francisco, 2001).

En definitiva, parece evidente que la seguridad por lo que respecta a la continuidad de unos ingresos básicos, que una Renta Básica garantiza por definición, haría posible no sólo negarse de forma efectiva y convincente a aceptar situaciones alienantes, de forma que se reduciría la dominación de unos individuos por parte de otros, sino también plantearse formas alternativas de organización del trabajo que permitieran aspirar a grados de realización personal más elevados. Por todo ello, cabe presentar la Renta Básica como un instrumento altamente valioso para aumentar la libertad como no-dominación de los individuos, para asegurar la libertad de cada cual para articular de forma autónoma unos planes

\footnotetext{
${ }^{14}$ Un ejemplo muy ilustrativo de ello puede encontrarse en Lerner, Clark y Needham (2001).

${ }^{15}$ Por otra parte, conviene no olvidar en este punto que la Renta Básica, al ser independiente de cualquier otra fuente de renta, evita las famosas trampas de la pobreza y del paro asociadas a los subsidios condicionados.
} 
RIS

REVISTA INTERNACIONAL DE SOCIOLOCIA

№34, Enero-Abril, 2003

DANIEL RAVENTÓS y DAVID CASASSAS

de vida propios sin que instancias externas puedan interferir en ello de forma arbitraria $^{16}$.

\section{RENTA BÁSICA Y COHERENCIA DE LAS TRAYECTORIAS PROFESIONALES Y PERSONALES}

A menudo se habla de la importancia de la coherencia de las trayectorias profesionales, ya que ésta ha de permitir concebir con cierto sentido la posibilidad de articular las identidades profesionales $\mathrm{y}$, con ellas, las identidades personales - y las morales, al fin y al cabo-; en definitiva, de la importancia para los individuos de encontrarse en condiciones de dar una respuesta coherente a la difícil pregunta del "qué soy"17.

No es necesario alinearse entre los que aseguran que la respuesta a la pregunta del "qué soy" - del "quién soy"- tenga que venir exclusivamente de la esfera del trabajo para asumir la importancia del hecho de que una Renta Básica, desde el momento en que aseguraría ciertos niveles de seguridad en los ingresos, permitiría que pudiese plantearse la posibilidad de ciertas formas de contratación - basadas en criterios de flexibilidad sin pérdida de seguridad, por ejemplo- que facilitarían mayores dosis de autorrealización por parte de los trabajadores.

Tal y como plantea Pinilla (2002), con una Renta Básica seguiría vivo el problema esencial relativo a la asignación de recursos escasos susceptibles de usos alternativos que se ha utilizado tradicionalmente para definir el objeto de estudio de la economía. Pero en una sociedad con la existencia garantizada, el recurso genuinamente escaso sería el tiempo ${ }^{18}$. Y, en concreto, el tiempo entendido como tiempo de vida de calidad. En efecto, una consecuencia de la introducción de una Renta Básica de nivel suficiente sería la disminución del atractivo del salario como

\footnotetext{
${ }^{16}$ Merece la pena detenerse un instante en la definición de la noción de libertad republicana como nodominación. Tal y como plantea Pettit (1999), libertad como nodominación es la que disfruta una persona cuando vive en presencia de otras personas y, en virtud de un determinado diseño social e institucional, no sólo ninguna de ellas interfiere de forma arbitraria en las decisiones que aquélla pueda tomar, sino que, además, nadie cuenta con la mera posibilidad de hacerlo. No es el objetivo de este artículo ni la exposición en detalle del ideario normativo republicano, ni la fundamentación republicana de la Renta Básica. Para una exposición del mencionado ideario, además de la ya casi popular obra de Pettit, debe leerse Domènech (1989 y 2003). Para un análisis pormenorizado de la Renta Básica como un instrumento capaz de dotar de mayor alcance e intensidad a la libertad republicana como nodominación, véanse Raventós (2000), Raventós y Casassas (2002), Francisco y Raventós (2003).

${ }^{17}$ Véase, para una perspectiva estrictamente sociológica de la cuestión, Sennett (1998). Para una aproximación desde las ciencias cognitivas al papel que juegan los procesos auto-narrativos de las propias trayectorias en el despliegue de las identidades personales, véase Flanagan (1996).

${ }^{18}$ Los planteamientos de Zubero (2001) distan bien poco de tales postulados.
} 
incentivo fundamental para trabajar. Es dable pensar que, con una Renta Básica, los motivos para trabajar en una u otra actividad tendrían que ver, cada vez más, con las preferencias personales, y menos con la remuneración esperada. De este modo, la extensión de una Renta Básica favorecería especialmente el fomento del trabajo a tiempo parcial, de la autoocupación y de las empresas de propiedad cooperativa, entre otras formas de organización del trabajo y de la producción. Con las formas de organización jerárquicas y autoritarias que caracterizan buena parte de las grandes empresas actuales y sin introducir cambios significativos en las condiciones de trabajo, sería difícil retener a los trabajadores en las ocupaciones actualmente mayoritarias (Pinilla, 2002). Con todo, con una Renta Básica se tendería hacia una mejor división y especialización del trabajo, así como hacia mayores niveles de libertad a la hora de enfocar y planificar la actividad productiva de acuerdo con las propias disposiciones, capacitaciones e intereses, vocaciones y ambiciones; de acuerdo, en definitiva, con la propia decisión de cada cual acerca de cómo quiere autorrealizarse (Gargarella, 1995; Van Parijs, 1996; Pinilla, 2001). En este punto, sin embargo, conviene clarificar qué tipo de flexibilidad se está barajando. Bajo la perspectiva que hemos manejado, con una Renta Básica las fórmulas contractuales como el trabajo a tiempo parcial no han de ser entendidas como una claudicación por parte de los trabajadores frente a políticas laborales como las que cierta izquierda española, por ejemplo, ha combatido desde principios de la década de 1990, sino como la manifestación inequívoca de un logro: el de la seguridad en los ingresos de los trabajadores y, de resultas de ésta, el de la posibilidad de plantearse fórmulas contractuales más flexibles con vistas a unos mayores niveles de realización personal no sólo en el ámbito del trabajo - remunerado - sino también en el resto de esferas de la vida cotidiana (Raventós, Noguera y Casassas, 2002; Red Renta Básica, 2002).

Un ejemplo extraído de una proyección hecha a partir de ciertas pautas de la vida cotidiana actual de los jóvenes -o de ciertos grupos de jóvenes, cabría matizar - bastará para clarificar este punto. Poder agregar "cuatro rentas básicas" de 350 euros ${ }^{19}$ mensuales cada una de ellas y, de este modo, poder emanciparse del hogar paterno; $y$, a la vez, poder compaginar un trabajo a media jornada en condiciones dignas con cierta vida asociativa o con cierta actividad creativa o del tipo que sea constituye un ejemplo, si se quiere, un tanto tópico, pero sin duda altamente ilustrativo de un posible cambio en las formas de gestión del tiempo y en la organización del trabajo y del ocio que puede ser de una hondísima importancia social y política.

\footnotetext{
${ }^{19}$ Esta cantidad no es arbitraria. Efectivamente, estos 350 euros mensuales corresponden aproximadamente al umbral de la pobreza medio del conjunto del territorio del Reino de España. Conviene notar, sin embargo, que si desagregáramos los cálculos por comunidades autónomas aparecerían diferencias significativas.
} 
RIS

REVISTA INTERNACIONAL DE SOCIOLOCIA

№ 34, Enero-Abril, 2003

DANIEL RAVENTÓS y DAVID CASASSAS

\section{CONCLUSIONES}

Éste es, pues, el auténtico alcance de la propuesta de la Renta Básica. Retrocedamos hasta los niveles de abstracción con los que se ha abierto el presente análisis: ¿podemos entender la seguridad en los ingresos que confiere una Renta Básica como condición necesaria de la propia ciudadanía?

$\mathrm{La}$ incondicionalidad con que se percibe la Renta Básica supone un salto cualitativo considerable con respecto a la situación actual. En efecto, si la Renta Básica se percibe de forma incondicional es porque la seguridad en los ingresos pasa a ser vista como un derecho de ciudadanía, un derecho por el cual cualquier ciudadano pasa a ser "propietario" - "propietario de su propia vida"- (Raventós y Casassas, 2002), tal y como ocurría en los esquemas tanto de Aristóteles como del pensamiento socialista que iba adquiriendo madurez durante la segunda mitad del siglo XIX.

$Y$ esta incondicionalidad con que se percibe la Renta Básica no constituye sólo una respuesta a las dificultades técnicas de los subsidios condicionados - cabe recordar otra vez el problema de la llamada "trampa de la pobreza" a la que conducen los subsidios condicionados, los cuales desincentivan la ocupación y estimulan la economía sumergida: "trabajo menos porque no quiero perder el subsidio de paro". La universalidad de la Renta Básica va más allá. La universalidad de la Renta Básica debe entenderse como una respuesta ante la evidencia de esa fractura del "tercer estado" que Sieyés no contempló y que Marx trató magistralmente: su escisión entre un grupo de burgueses propietarios, realmente libres, y otro grupo formado por los proletarios, por los trabajadores asalariados, por los individuos dependientes, por los que "viven con permiso de otros", en último término. En este sentido, la garantía incondicional de una Renta Básica, que es la garantía de la seguridad económica para "decir que no", permitiría el tránsito de un esquema de derechos formalmente garantizados a otro que bascule alrededor de la noción de libertad real y que, con ella, garantice que los derechos formales devengan reales para todos los individuos, sin distinción alguna, y actúe como muro de contención con respecto a cualquier forma de dominación que se pueda dar en el seno de la sociedad civil. Y esto, desde una óptica política, no es poca cosa: se trata de que todos los individuos - toda la sociedad civil- sean realmente libres ${ }^{20}$.

En efecto, bajo tal perspectiva, el hecho de que la Renta Básica garantice la seguridad económica ex-ante y no ex-post - así es como funcionan hoy buena

\footnotetext{
${ }^{20}$ Pese a tratarse de enfoques conceptualmente distintos, el punto de engarce entre los planteamientos que hemos ido desgranando y el esquema ético-normativo de Philippe Van Parijs (1996), el liberal de extrema izquierda -según la definición que dio de sí mismo- responsable de la irrupción en la academia de la propuesta de la Renta Básica, aparece en este punto de forma clara.
} 
parte de los sistemas de garantía de ingresos y de protección social: entran en acción una vez que se ha puesto de manifiesto la situación de pobreza que se debe combatir - presenta un buen número de ventajas de tipo técnico que ya han sido apuntadas; pero, sobre todo, tiene un significado ético, sociológico y político de gran profundidad.

\section{BIBLIOGRAFÍA}

BERTOMEU, M. J. (2003), "Las raíces republicanas del mundo moderno", en M. J. Bertomeu, A. Domènech y A. de Francisco, Republicanismo y democracia, Madrid, Trotta (en prensa).

CASASSAS, D. y G. LOEWE (2001), "Renta Básica y fuerza negociadora de los trabajadores", en Raventós, D. (coord.), La Renta Básica. Por una ciudadania más libre, más igualitaria y más fraterna, Barcelona, Ariel.

DOMÈNECH, A. (1989), De la ética a la política, Barcelona, Crítica.

(2003), El eclipse de la fraternidad, Barcelona, ed. Crítica (en prensa).

ELSTER, J. (1991), El cemento de la sociedad, Barcelona, Gedisa.

FLANAGAN, O. (1996), Self Expressions: Mind, Morals and the Meaning of Life, Oxford, Oxford University Press.

FRANCISCO, A. de (2001), "Utopía y realidad”, Revista de Libros, n. 50, pp. 22.

FRANCISCO, A. de y D. RAVENTÓS (2003), "Republicanismo y Renta Básica", en M. J. Bertomeu, A. Domènech y A. de Francisco, Republicanismo y democracia, Madrid, Trotta (en prensa).

FRANK, R. (1999), Luxury Fever, Nueva York, Free Press.

GARGARELLA, R. (1995), "El ingreso ciudadano como política igualitaria”, en Lo Vuolo, R. (comp.), Contra la exclusión. La propuesta del ingreso ciudadano, Buenos Aires, Ciepp/Miño y Dávila Editores.

GIARINI, O. y P.M. LIEDTKE (1998), El dilema del empleo. Informe al Club de Roma, Barcelona, Galaxia Gutenberg-Círculo de Lectores.

LERNER, S., C.M.A. CLARK y R. NEEDHAM (2001), "Un modelo de Renta Básica para Canadá", en Raventós, D. (coord.), La Renta Básica. Por una ciudadania más libre, más igualitaria y más fraterna, Barcelona, Ariel.

MARX, K. (1981), “Crítica del programa de Gotha”, en Marx-Engels, Obras escogidas, Moscú, Progreso.

MUNDÓ, J. (2003), “Autopropiedad, derechos y libertad (¿debería estar permitido que uno pudiera tratarse a sí mismo como a un esclavo?)", en M. J. Bertomeu, A. Domènech y A. de Francisco, 
RIS

Republicanismo y democracia, Madrid, Trotta (en prensa).

NOGUERA, J.A. (2001), “¿Renta Básica o trabajo básico?”, ponencia presentada en el I Simposio de la Renta Básica, organizado por la Red Renta Básica (Barcelona, 8 de junio de 2001). Puede encontrarse en la web de la asociación Red Renta Básica: www.redrentabasica.org.

NOGUERA, J.A. y D. RAVENTÓS (2002a), "La Renta Básica de ciudadanía: acerca de su justicia, el derecho al trabajo y la polarización social”, Claves de Razón Práctica, n. ${ }^{\circ} 120$, pp. 33-43.

(2002b), "Basic Income, Social Polarization and the Right to Work", ponencia presentada en el $9^{\text {th }}$ Congress of the BIEN (Ginebra, 12-14 de Septiembre de 2002).

NOZICK, R. (1974), Anarchy, State, and Utopia, Nueva York, Basic Books.

PETTIT, P. (1999), Republicanismo. Una teoria sobre la libertad y el gobierno, Barcelona, Paidós.

PINILLA, R. (2001), “¿Es posible una Renta Básica eficiente? Evaluación económica de la Renta Básica", en Raventós, D. (coord.), La Renta Básica. Por una ciudadania más libre, más igualitaria y más fraterna, Barcelona, Ariel.

(2002), "La Renta Básica, de la economía de la escasez a la economía de la abundancia", $E l$ Vuelo de Ícaro. Revista de Derechos Humanos, Critica Politica y Análisis de la Economia, n. ${ }^{\circ}$ 2-3, pp. 127-143.

RAVENTÓS, D. (1999), El derecho a la existencia. La propuesta del Subsidio Universal Garantizado, Ariel, Barcelona.

(2000), "El salario de toda la ciudadanía", Claves de Razón Práctica, n. ${ }^{\circ} 106$, pp. 43-48.

(2002), "Detrás de la desigualdad hay un problema de libertad o "los que viven con permiso de otros" (esbozo de una propuesta para una ciudadanía libre de dominación)", El valor de la palabra, n. ${ }^{\circ} 2$, pp. 78-102.

RAVENTÓS, D. y D. CASASSAS (2002), "Republicanism and Basic Income: the articulation of the public sphere from the repoliticization of the private sphere", ponencia presentada en el $9^{\text {th }}$ Congress of the BIEN (Ginebra, 12-14 de Septiembre de 2002).

RAVENTÓS, D. y A. de FRANCISCO (2002), “Ricos y pobres”, El Pais, 16-11-2002.

RAVENTÓS, D., J.A. NOGUERA y D. CASASSAS (2002), "Catorce respuestas sobre la Renta Básica", El Ciervo, n. ${ }^{\circ} 610$, pp. 18-23.

RED RENTA BÁSICA (2002), La Renta Básica, Red Renta Básica, Barcelona.

SENNET, R. (2000), La corrosión del carácter. Las consecuencias personales del trabajo en el nuevo capitalismo, Barcelona, Anagrama.

SIEYÉS, E. (1989), Qué es el Tercer Estado?, Vilassar de Mar, Oikos-Tau. 
SUPLICY, E.M. (2002), Renda de cidadania, Sao Paulo, Cortez-Fund. Perseu Abramo.

URIBARRI, I. (2002), "Notas sobre el sindicato ELA", Viento Sur, n. ${ }^{\circ} 63$, pp. 71-77.

VAN DER VEEN, R., L. GROOT y R. LO VUOLO (eds.) (2002), La Renta Básica en la agenda, Buenos Aires, Ciepp/Miño y Dávila Editores.

VAN PARIJS, P. (1992), “Competing Justifications of Basic Income”, en Van Parijs, P. (ed.), Arguing for Basic Income: Ethical Foundations for a Radical Reform, Londres, Verso.

(1996), Libertad real para todos. ¿Qué puede justificar al capitalismo, si hay algo que pueda hacerlo?, Barcelona, Paidós.

ZUBERO, I. (2001), "Repensar el empleo, repensar la vida”, en Raventós, D. (coord.), La Renta Básica. Por una ciudadania más libre, más igualitaria y más fraterna, Barcelona, Ariel. 